\title{
AVALIAÇÃO COMPARATIVA DE MÉTODOS DE ENSAIO IMUNOENZIMÁTICO PARA THEILERIA EQUI DE AMOSTRAS DE SORO EQUINO DO ESTADO DE SÃO PAULO
}

\author{
COMPARATIVE EVALUATION OF METHODS OF IMMUNOENZYMATIC ASSAY FOR \\ THEILERIA EQUI OF SAMPLES OF EQUINE SERUM OF THE STATE OF SÃO PAULO
}

\author{
A. C. PARRA ${ }^{1 *}$, M. A. PIOTTO ${ }^{2}$, C. R. FRESCHI ${ }^{3}$, \\ R. Z. MACHADO ${ }^{4}$, W. R. FERNANDES ${ }^{5}$
}

\begin{abstract}
RESUMO
A presente pesquisa teve como objetivo comparar a sensibilidade e especificidade de dois testes diagnósticos, um ELISA indireto e um ELISA competitivo,para Theileria equi,com a finalidade de disponibilizar um teste alternativo para o diagnóstico da babesiose em rebanhos equinos em território nacional. Foram avaliadas 168 amostras de soro equino (suspeitos ou não para babesiose), com idade mínima de um ano, independente de sexo, raça e manejo. Os testes foram realizados segundo especificações de cada fabricante. Os resultados obtidos foram analisados estatisticamente pelo Teste do Qui-quadrado. A concordância entre os testes foi de 97,2\% entre os animais soropositivos (105 soropositivos no c-ELISA e 108 soropositivos no ELISA indireto) e 95,2\% dos animais soronegativos (63 soronegativos no c-ELISA e 60 soronegativos no ELISA indireto). Não foram observadas diferenças estatisticamente significativas entre os dois testes. Concluiu-se que o teste ELISA indireto apresentou alta sensibilidade e especificidade (98,1\% e 92,1\%, respectivamente) para o diagnóstico de Babesiose por Theileria equi.
\end{abstract}

PALAVRAS-CHAVE: Babesia equi. Theileria equi. Elisa indireto. ELISA competitivo. Equinos.

\section{SUMMARY}

The present research had as objective to compare thesensitivity and specicvityof the tests of indirectELISA e competitive ELISA for Theileria equi, with purpose to evaluate an alternative test for control of babesiose in equinos flocks in domestic territory. 168 samples of equine serum had been evaluated (suspected or babesiosis does not stop), with minimum age of one year, independent of sex, race and handling. The tests had been carried through according to specifications of each manufacturer, following orientations of each one. The gotten results had been analyzed statistical by the Test of the Qui-quadrado. As result, agreement was observed enters the tests of 97,2\% of soropositives animals (105 soropositives in c-ELISA and 108 soropositives in the indirect ELISA) and $95.2 \%$ of the soronegatives animals (63 soronegatives in c-ELISA and 60 soronegatives in the indirect ELISA). Statistical significant differences between Indirect and competitive test ELISA for Theileria equi had not been observed. It is concluded that indirect test ELISA showed high sensitivity and specificity $(98,1 \%$ e $92,1 \%$, respectively) for the diagnosis of Babesiosis by Theileria equi.

KEY-WORDS: Babesia equi. Theileria equi. Indirect ELISA. Competitive ELISA. Equine.

\footnotetext{
${ }^{1}$ Médica Veterinária, Doutora em Ciências pelo Departamento de Clínica Médica - FMVZ -USP. Av. Professor Orlando Marques Paiva, 87, CEP 05508-270, Faculdade de Medicina Veterinária e Zootecnia da Universidade de São Paulo, Cidade Universitária, Butantã, São Paulo, SP, Brasil. Email: *acparra@usp.br

${ }^{2}$ Médica Veterinária, Mestre em Ciências pelo Departamento de Clínica Médica -FMVZ - USP.

${ }^{3}$ Médica Veterinária, Pós-doutoranda pelo Departamento de Patologia Veterinária - FCAVJ - UNESP - Jaboticabal - SP.

${ }^{4}$ Professora Livre docente do Departamento de Patologia Veterinária - UNESP - FCAVJ - Jaboticaabal - SP.

${ }^{5}$ Professor Titular do Departamento de Clínica Médica - FMVZ-USP.
} 


\section{INTRODUÇÃO}

Babesiose equina é uma doença causada por protozoários intraeritrocíticos, Theileria equi e Babesia caballi, equi possui como principal transmissor os carrapatos (CRIADO-FORNELIO et al, 2003).É uma das doenças de maior importância econômica no mercado equino (MELHORN e SCHEIN 1998), sendo considerada a mais patogênica e a causa mais consistente de hemoglobinúria e morte em equinos (ZAUGG e LANE, 1992).

A babesiose é uma doença cosmopolita, bastante encontrada nas áreas tropicais e subtropicais do mundo, bem como em algumas regiões de clima temperado (DE WAAL, 1992). A ampla distribuição geográfica da babesiose equina está intimamente relacionada às áreas de maior concentração dos seus vetores (FRIEDHOFF, 1998). Segundo Friedhoff et al. (1990), é considerada emergente nos países subtropicais e está presente em áreas que abrigam $90 \%$ da população equina mundial.

Nos equinos infectados por T. equi, a doença se caracteriza por febre, anemia, icterícia, hepatomegalia, esplenomegalia, hemoglobinúria e em alguns casos pode levar o animal a morte (SCHEIN, 1998). No entanto, a maioria dos animais que se recuperam de uma infecção aguda ou primária, são portadores do parasito por vários anos, tornando-se reservatórios para os carrapatos vetores (CACCIO et al., 2000; KNOWLES, 1996). Além disso, a infecção por T. equi pode ser suprimida por quimioterápicos, mas não pode ser completamente eliminada (DE WALL \& VAN HEERDEN, 1994).

Os carrapatos desempenham importante papel na transmissão da babesiose equina. Na América, os vetores de $T$. equi citados até o momento são Dermacentor variabilis e Rhipicephalus (Boophilus) microplus, ambos identificados como transmissores experimentais (GUIMARÃES, 1998ab). No Brasil, as principais espécies que parasitam os eqüídeos são $D$. nitens e Amblyomma cajennense. No entanto, experimentalmente, foi evidenciado que esses carrapatos são incapazes de transmitir $T$. equi (STILLER \& COAN, 1995). Estudos mais recentes demonstram a importância do $R$. microplus como parasito de equinos (GUIMARÃES et al., 1998ab; BATTSETSEG et al., 2002) e indicam a sua importância comotransmissor natural de $T$. equi e $B$. caballi. Guimarães et al. (1998ab) concluíram, experimentalmente, que o B. microplus pode funcionar como vetor natural de $T$. equi,uma vez que os esporozoítos são capazes de completar seu desenvolvimento nesse carrapato, que por sua vez, pode transmitir o parasito para outro hospedeiro. A transmissão do parasito também pode ocorrer através de instrumentos veterinários (FARIAS, 2001) e por via transplacentária. RONCATI (2006) avaliou 50 potros (machos e fêmeas) e suas respectivas mães, logo após o parto, utilizando as técnicas de Real Time PCR e cELISA (ensaio imunoenzimático competitivo VRMD $\left.{ }^{\circledR}\right)$, e concluiu que $46 \%$ das éguas apresentaram resultado positivo para Theileria equi e $73 \%$ dos potros positivos nasceram de mães positivas.

A Babesiose equina pode causar redução de rendimento atlético, abortamento, infecções agudas e morte dos animais acometidos. Além disso, há de se considerar os prejuízos econômicos decorrentes de dificuldade de comercialização (importação e exportação) e a proibição de participação em competições internacionais de animais soropositivos. A morte e a ocorrência de infecção aguda secundária não são tão comuns em áreas endêmicas, mas podem ocorrer quando da reagudização dos quadros crônicos, principalmente em função do estresse ou de doença concomitante (WALL, 1992; BARBOSA et al., 1995; FARIAS, 2001; NAGORE et al., 2004)

As babesioses equinas, causadas por Theileria equi e Babesia caballi, são enfermidades sanguíneas de grande importância na Medicina Veterinária, acometendo várias espécies animais principalmente equinos (MUNDIM et al., 2008), são endêmicas em muitas regiões do mundo e apresentam alta prevalência (TEGLAS et al., 2005).

Em rebanhos equinos, a piroplasmose promove consideráveis perdas econômicas, tanto em relação aos gastos relacionados a tratamento e manutenção dos animais, como também, prejudicando o treinamento e acondicionamento de importantes e valiosos animais atletas (FRIEDHOFF, 1988).

O método diagnóstico para detecção e identificação destes parasitas mais utilizado no meio equino é o exame microscópico de esfregaço sanguíneo. Este método é pouco sensível devido à dificuldade da observação do parasito em casos de animais que apresentem baixa parasitemia e em casos agudos no início da doença. Outros métodos de diagnóstico são: teste de fixação de complemento (CFT) e o teste indireto do anticorpo fluorescente (IFAT) que podem ser úteis para detectar infecções antigas, mas reações cruzadas entre espécies já foram relatadas (BRUNING, 1996). Atualmente, um dos métodos de diagnóstico utilizado para a Babesiose equina, tanto por Theileria equi como para Babesia caballi é o ELISA competitivo (c-ELISA). Esse KIT diagnóstico comercial foi desenvolvido nos EUA, utilizando cepas isoladas na região, e é recomendado pela OIE (Organização Internacional de Epizootias Organização Mundial de Saúde Animal), mostrando ser o teste padrão para trânsito internacional de equinos (LNIV, 2009). O ensaio imunoenzimático competitivo (c - ELISA) tem como princípio o bloqueio da atividade de uma enzima previamente marcada, na qual amostras suspeitas (com ou sem anticorpos específicos) são desafiadas em um recipiente com antígenos específicos. Caso essas amostras possuam anticorpos, estes irão ligar-se aos antígenos, bloqueando estes epítopos, inibindo a ligação das enzimas-marcadas. Quanto mais anticorpos presentes na amostra testada, menor será a coloração da reação.Outra técnica é oensaio imunoenzimático indireto (iELISA) que dá-se pelo princípio do anticorpo presente na amostra ser envolvido entre o antígeno que reveste a placa experimental e uma enzima-marcada. A adição de uma 
enzima reagente substrato-cromogênica promove uma cor ao ligar-se ao conjugado antígeno-anticorpo. A coloração produzida na reação é diretamente proporcional à quantidade de anticorpos presentes na amostra suspeita (TIZARD, 2004; IDEXX Laboratories 2007).As técnicas de biologia molecular, como PCR (polimerase chain reaction - reação em cadeia pela polimerase) provaram ser muito úteis para a detecção e a identificação de muitas espécies de hemoparasitas como do grupo de Theileria/Babesia (CACCIO et al, 2000). Estes métodos são baseados em ensaios espécie-específico, que almejam principalmente o gene do rRNA 18S (SPARAGANO, 1999), mas protocolos esclusivos da amplificação são necessários para cada espécie, mostrando serem mais específicos, quando comparados a técnicas sorológicas e exame direto de esfregaço sanguíneo.

O presente trabalho teve como objetivo avaliar dois testes imunoenzimáticos, um que utiliza como antígeno a proteína recombinante EMA1 (c-ELISA) de Theileria equi, sendo este classificado com PadrãoOuro (gold standard test), e os outros antígenos solúveis totais (ELISA indireto - iELISA) de Theileria equi analisando sensibilidade e especificidade diagnósticas do iELISA, visto que c-ELISA utiliza-se anticorpos monoclonais, o que o torna mais específico. E ainda verificar se o kit ELISA indireto pode ser utilizado como técnica de rotina para controle de babesiose em rebanho nacionais.

\section{ANÁLISE ESTATÍSTICA}

Para avaliação estatística dos testes imunoenzimáticos envolvidos no presente trabalho, foi utilizado o Coeficiente de KAPPA, definido como uma medida de associação usada para descrever e testar o grau de concordância (confiabilidade e precisão) na classificação em questão (KOTZ, 1983).

\section{MATERIAL E MÉTODOS}

Foram utilizadas 168 amostras de soro equino (suspeitos ou não para babesiose), com idade mínima de 1 ano, independente de sexo, raça e manejo. Desse total, 82 amostras foram colhidas mediante atendimento no Setor de Equinos do Hospital Veterinário da Faculdade de Medicina Veterinária e Zootecnia da Universidade de São Paulo e as outras 86 amostras de animais provenientes de propriedades localizadas no Estado de São Paulo. As amostras foram colhidas por venopunção, com a utilização de tubos estéreis a vácuo (sistema de vacuntainer ${ }^{\circledR}$ ) com gel ativador de coágulo, para obtenção de soro. Após colheita elas foram centrifugadas, acondicionadas em microtubos identificados e armazenadas a $-20^{\circ} \mathrm{C}$ para posterior análise.

As amostras de soro colhidas foram testadas utilizando o kit c-ELISA (ensaio imunoenzimático competitivo, VMRD® - Pullman, WA, USA) e kit ELISA indireto desenvolvido por BALDANI e colaboradores (2004), pré-sensibilizadas com antígeno de Theileria equi.

Para realização do ensaio c-ELISA, tanto os soros a serem testados como os soros controles (positivo e negativo) foram diluídos com solução tampão (PBS - Tampão fosfato salino) na proporção 1:2. Destas soluções, foi transferido para cada poço da placa-teste, já sensibilizada com antígeno de Theileria equi, $50 \mu \mathrm{l}$ de cada amostra. Incubou-se a placa por 30 minutos em temperatura ambiente. Foram realizadas três lavagens da placa com solução própria para lavagem. Após obtenção da placa lavada e seca, houve adição de $50 \mu \mathrm{l}$ de anticorpo primário em cada poço e incubação da placa por 30 minutos em temperatura ambiente. Foram realizadas três lavagens da placa e

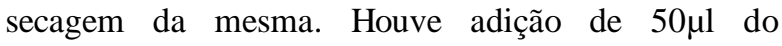
anticorpo secundário em cada poço e incubação da placa por 30 minutos em temperatura ambiente. Foram realizadas três lavagens da placa e secagem. Houve adição de $50 \mu \mathrm{l}$ de substrato em cada poço e incubação da placa por 15 minutos em temperatura ambiente, protegida de luz. Após a incubação, foi adicionado $50 \mu 1$ de solução de parada (da reação) em cada poço e realizada a leitura da placa em leitora de microplaca para ensaio imunoenzimático, no comprimento de onda de $630 \mathrm{~nm}$.

O ELISA indireto foi realizado conforme metodologia descrita por Baldani et al. (2004). Resumidamente, a placa foi sensibilizada com $10 \mu \mathrm{g} / \mathrm{mL}$ de antígeno bruto de $T$. equi diluído em tampão carbonato-bicarbonato (pH 9,6). Após incubação "overnight" a $4^{\circ} \mathrm{C}$, o excesso de antígeno foi removido por três lavagens em PBS Tween $80(\mathrm{pH} 7,4)$. A placa foi bloqueada com PBS Tween 80 , acrescido de $6 \%$ de leite em pó desnatado e incubada a $37^{\circ} \mathrm{C}$ por 90 minutos. Os anticorpos não ligados foram removidos por lavagens como descrito acima. Cem microlitros de conjugado anti-IgG equino, diluído conforme preconizado pelo fabricante (Sigma Chemical Co.), foi adicionado a cada poço, seguindo-se nova incubação a $37^{\circ} \mathrm{C}$ por 90 minutos. A placa foi lavada e o substrato apropriado ( $\rho$ nitrofenilfosfato - $\rho$ NPP) foi adicionado. Após 30 minutos de incubação em temperatura ambiente, a leitura da reação foi realizada em leitor de microplacas de ELISA, a um comprimento de onda de $405 \mathrm{~nm}$.

\section{RESULTADOS E DISCUSSÃO}

Das 168 amostras de soro equino analisadas, 63 foram negativas pelo c-ELISA (VRMD $®$ ) e 60 foram negativas pelo ELISA indireto, como mostrado na Tabela 1.

No c-ELISA, $37,5 \%$ (63/168) dos animais foram soronegativos para T. equi, enquanto, $35,7 \%$ (60/168) se mostraram soronegativos pelo ELISA indireto, o que mostra uma concordância de 96,7\% entre os testes em questão. Esses dados corroboram com os achados de Baldani et al. (2004) que demonstraram alta sensibilidade do ELISA indireto, indicando que este teste pode ser apropriado para estudos epidemiológicos no Brasil. Asenzo et al. (2008), comparando o ELISA indireto desenvolvido pelo Centro de Pesquisas Veterinárias da Argentina com o c-ELISA (VRMD $®)$, demonstraram uma especificidade de 99,5\% em ambos os testes. 
Tabela 1 - Resultados dos testes c - ELISA (ensaio imunoenzimático competitivo - VMRD $®$ ) e ELISA indireto (ensaio imunoenzimático indireto, (BALDANI et al., 2004)) para Theileria equi em soro de equinos do Estado de São Paulo, 2012.

\begin{tabular}{ccccc}
\hline & \multicolumn{4}{c}{ c -ELISA } \\
\cline { 2 - 5 } & + & + & - & Total \\
\hline i - ELISA & $103(61,3 \%)$ & $5(2,9 \%)$ & $108(64,2 \%)$ \\
& - & $2(1,19 \%)$ & $58(34,5 \%)$ & $60(35,8 \%)$ \\
Total & $105(62,5 \%)$ & $63(37,5 \%)$ & $168(100 \%)$ \\
\hline
\end{tabular}

$\mathrm{Na}$ presente pesquisa, os resultados observados demonstram uma concordância entre os testes de $97,2 \%$ dos animais soropositivos e de 95,2\% dos animais soronegativos para T. equi, o que mostra que o ELISA indireto é tão sensível como o c-ELISA (Standard test segundo OIE - World Organisation for Animal Health) no diagnóstico de theileirose em eqüinos, mostrando sensibilidade de $98,1 \%$ e especificidade de $92,1 \%$, segundo cálculos sugeridos por MARTIN et al, (1994).

Os valores obtidos entre os métodos diagnósticos foram submetidos ao Teste de Qui quadrado $\left(X^{2}\right)$, o qual não demonstrou diferença significativa, evidenciando a confiabilidade do ELISA Indireto comparado ao ELISA competitivo, o qual é recomendado pela OIE (Organização Mundial de Saúde Animal) (LNIV,2009).

O estudo realizado demonstrou que os métodos diagnósticos para Theileria equi empregados neste estudo, ELISA competitivo e ELISA indireto, não apresentaram diferenças estatisticamente significativas, mostrando que a produção de anticorpos foi suficiente para ser detectadas em ambos os testes.

Adicionalmente, o uso de antígenos produzidos por cepas brasileiras, no teste de ELISA indireto, diminui a possibilidade da existência de diferenças antigênicas entre isolados de regiões diferentes, tornando o teste espécie-específico (BALDANI et al., 2004).

\section{CONCLUSÃO}

Em conclusão, o método imunoenzimático indireto (iELISA) apresentou alta sensibilidade e especificidade $(98,1 \%$ e $92,1 \%$, respectivamente) para o diagnóstico de Babesiose por Theileria equi, podendo ser utilizado no controle de rotina para Babesiose em rebanhos nacionais, oferecendo vantagens como menor preço e facilidade de aquisição por amostra e apropriado para estudos epidemiológicos.

\section{AGRADECIMENTOS}

À FAPESP (Fundação de Amparo à Pesquisa do Estado de São Paulo) pelo Auxílio para realização do presente estudo (Processo: 07/ 53.987-6).

COMITÊ DE ÉTICA E BIOSEGURANÇA: Certificado da Comissão de Bioética protocolado sob o n¹124/2007, da Faculdade de Medicina Veterinária e Zootecnia da Universidade de São Paulo, aprovado em reunião em 22 de agosto de 2007.

\section{REFERÊNCIAS}

ASENZO, G.; WILKOWSKY, S.; BARRANDEGUY, M.; MESPLET, M.; BENITEZ,D.; FLORINCHRISTENSEN, M. Development of an Indirect ELISA for the Diagnosis of Equine Piroplasmosis. Animal Biodiversisity and Emerging Diseases: Annals of the New York Academy of Sciences, v.1149, p.235-238. 2008.

BALDANI, C. D.; MACHADO, R. Z; BOTTEON, P. T. L.; TAKAKURA, F. S.; MASSARD, C. L. Enzymelinked immunosorbent assay for the detection of $\mathrm{IgG}$ antibodies against Babesia equi in horses. Ciência Rural, Santa Maria, v.34, n.5, p.1525-1529, set-out, 2004.

BARBOSA, I. P.; BOSE, R.; PEYMANN, B.; FRIEDHOFF, K. T. Epidemiological aspects of equine babesioses in a herd of horses in Brazil. Veterinary Parasilotogy, v.58, p.1-8.1995.

BATTSETSEG, B.; LUCERO, S.; XUAN, X.; CLAVERIA, F. G.; IVONE, N. Detection of natural infection of Boophilus microplus with Babesia equi and Babesia caballi in Brazilian horses using nested polymerase chain reaction. Veterinary Parasilotogy, v.107, n.4, p.351-357, 2002.

BRUNING, A., 1996.Equine piroplasmosis an update on diagnosis. British Veterinary Journal, 152, p.139151.

CACCIO, S., CAMMA, C., ONUMA, M., SEVERINI, C. The beta-tubulin gene of Babesia and Theileria parasites is an informative marker for species discrimination. Int. Veterinary Parasilotogy. 30, p.1181-1185. 2000.

CRIADO-FORNELIO, A.; MARTINEZ-MRCOS, A.; BULING-SARANA, A.; BARBARA-CARRETERO, J. C. Molecular studies on Babesia. Theleiria and 
hepathozoon in Southern Europe: part I. Epizootiological aspects. Veterinary Parasitology. v.113, p.189-201. 2003.

CUNHA, C. W. Babesiose equina: Padronização da reação de imunofluorescência para sorodiagnóstico e levantamento epidemiológico em equinos Puro Sangue Inglês. Universidade Federal de pelotas. Pelotas, 1993.

DE WAAL, D.T. Equine piroplasmosis: a review. British Veterinary Journal, v.148, p.6-14, 1992.

DE WAAL, D. T.; HEERDEN, J. V. Equine babesiosis.In: JAW, C., THOMSON, G. R., TUSTIN, R. C. (Ed.). Infectious diseases of livestock with special reference to South Africa.vol. 1. Oxford: University Press, 1994. p.293-304.

FALCE, H. C.; FLECHTMANN, C. H. W.; FERNADEZ, B. C. Ixodidaede (Acari) on horses, mules and asses in the state of Paraná, Brazil. Revista da Faculdade de Medicina Veterinária e Zootecnia da Universidade de São Paulo. v.20. p.103-106. 1983.

FARIAS,N. A babesiose equina. In: RIET-CORREA, F; SCHILD, A. L.; MENDEZ, M. D. C.; LEMOS, R. A. A. Doenças de Ruminantes e equinos . São Paulo: Livraria Varela, v.2, p.42-7. 2001.

FREIRE, J. J. Revisão das espécies da Família Ixoddidae. Revista Medicina Veterinária, v.8. p.1-16. 1972.

FRIEDHOFF, K. T. Transmition of Babesia. In:_ Babesiose in domestics animals and man. Boca Raton. Florida, C.R.C press. 1988. p.23-52.

FRIEDHOFF, K. T.; TENTER, A. M.; MULLER, I. Haemoparasites of equines: impact on internacional trade of horses. Revue Scientifique et Technique, v.9, n.4, p.1187-1194, 1990

KOTZ, S; JOHNSON, N. L. Encyclopedia of statistical sciences. New York: John Wiley \& Sons; 1983. v.4, p.352-4.

HEIM, A.; PASSO, L. M. F.; RIBEIRO, M. F. B.; COSTA-JUNIOR, L. M.; BASTOS, C. V.; CABRAL, D. D.; HIRZMANN, J.; PFISTER, K. Detection and molecular characterization of Babesia caballi and Theileria equi isolates from endemic areas of Brazil. Parasitology Research ,v.102, p.63-68. 2007

GUIMARÃES, A. M.; LIMA, J. D.; RIBEIRO, M. F. B. Sporogony and experimental transmission of Babesia equi by Boophilus microplus. Parasitology Research. v.84.p.323-327. 1998a.

GUIMARÃES, A.M. et al. Ultrastructure of sporogony in Babesia equi in salivary glands of adult female Boophilus microplus ticks. Parasitology Research., v.84, n.1, p.69-74, 1998 b.
IDEXX

Laboratories.

http://www.idexx.com/production/elisa/ . Acesso em 14 de fevereiro de 2011.

KNOWLES, D. P. Control of Babesia equi parasitemia. Parasitology Research., v.12, p.195-198, 1996.

LNIV. Laboratório Nacional de Investigação Veterinária. http://www.Iniv.minagricultura.pt/PresentationLayer/lniv_conteudoAgregad or.aspx ?itemMenu=160\&menuID=160 . Acesso em 12 de maio de 2009.

MARTIN S. W., MEEK A. H. \& WILLEBERG P. 1994. Measurement of disease frequency and production, p. 48-76. In: MARTIN S. W., MEEK A. H. \& WILLEBERG P. (ed.) Veterinary Epidemiology. Principles and Methods. Iowa State University Press, Ames.

MELHORN, H.; SCHEIN, E. Redescription of Babesia equi Laveran, 1901 as Theileria equi Melhorn, Schein. Parasitology Research, v.84, p.467-475. 1998.

MUNDIM, E. C. S.; FRANCISCO, M. M. S.; SOUZA, J. N.; ALENCAR, M. A. G.; RAMALHO, P. C. D. Incidência de hemoparasitoses em cães (Canis familiares) capturados em rua pelo Centro de Controle de Zoonoses (CCZ) da cidade de Anápolis - GO. Ensaios e ciência: Ciências biológicas, agrárias e da saúde. Vol.XII, n.2. Ano 2008.

NAGORE, D.; GARCIA-SANMARTIN, J.; GARCIAPEREZ, A. L.; JUSTE, R. A.; HURTADO, A. Detection and identification of equine Theileria andBabesia species by reverve line boting: epidemiological survey and phylogenetic analysis. Veterinary Parasitology, v.123, p.41-54, 2004.

RONCATI, N. W. Ocorrência de Theileria equi congênita em potros Puro Sangue Lusitano no Brasil, diagnosticada atravésa da técnica de RT - PCR. Tese (doutorado). Universidade de Sâo Paulo. Faculdade de Medicina Veterinária e Zootecnica. Departamento de Clínica Médica. 69.f. 2006

SCHEIN, E. Equine babesiosis. In: RISTIC, M. (Ed.). Babesiosis of domestic animals and man. Boca Raton: CRS Press, 1998. p. 197-208.

SPARAGANO, O. Molecular Diagnosis of Theileria and Babesia species.J. Veterinary Parasitology. v.13, p.83-92.1999.

STILLER, D.; COAN, M.E. Recent developments in elucidating tick vector relationship for anaplasmosis and equine piroplasmosis. Veterinary Parasitology, v.57, p.97-108, 1995. 
TIZARD, I. R. Immunodiagnostic techniques.2004. In: TIZARD, I. R. Veterinary Immunology - an introduction. $7^{\text {th }}$. Edition. Saunders.

TEGLAS M.; MATERN E.; LEIN S.; FOLEY P.; MAHAN S. M.; FOLEY J. Ticks an tick-borne disease in Guatemalan cattle and horses. Veterinary Parasitology. v.131 (2005), p.119-127.

WALL, D. T. Equine piroplasmosis: a review. British Veterinary Journal. v.148, p.06 - 14. 1992.

ZAUGG, J. L.; LANE, V. M. Efficacy of buparvaquone as a therapeutic and clearing agent of Babesia equi of European origin in horses. American Journal Veterinary Research, v.53, p.1396-1399. 1992. 